\title{
Stereotactic body radiation therapy with or without transarterial chemoembolization for patients with primary hepatocellular
} carcinoma: preliminary analysis

\author{
Byung Ock Choi ${ }^{1}$, Ihl Bohng Choi ${ }^{\dagger 1}$, Hong Seok Jang ${ }^{1}$, Young Nam Kang ${ }^{1}$, \\ Ji Sun Jang1, Si Hyun Bae², Seung Kew Yoon², Gyu Young Chai ${ }^{3}$ and \\ Ki Mun Kang*†3
}

Address: ${ }^{1}$ Department of Radiation Oncology, The Catholic University of Korea, School of Medicine, Seoul, South Korea, ${ }^{2}$ Department of Internal Medicine, The Catholic University of Korea, School of Medicine, WHO Collaborating College of Medicine, Seoul, South Korea and ${ }^{3}$ Department of Radiation Oncology, Gyeongsang National University, College of Medicine, Gyeongsang Institute of Health Sciences, Jinju, South Korea

Email: Byung Ock Choi - choibo67@catholic.ac.kr; Ihl Bohng Choi - ibchoi53@yahoo.co.kr; Hong Seok Jang - hsjang11@catholic.ac.kr; Young Nam Kang - k3yn@ @atholic.ac.kr; Ji Sun Jang - soulson@empal.com; Si Hyun Bae - shbae@catholic.ac.kr;

Seung Kew Yoon - yoonsk@catholic.ac.kr; Gyu Young Chai - cgyinj@dreamwiz.com; Ki Mun Kang* - jsk92@gnu.ac.kr

* Corresponding author †Equal contributors

Published: 27 November 2008

BMC Cancer 2008, 8:35I doi:10.1 I86/I47|-2407-8-35I
Received: 6 March 2008

Accepted: 27 November 2008

This article is available from: http://www.biomedcentral.com/I47I-2407/8/35 I

(c) 2008 Choi et al; licensee BioMed Central Ltd.

This is an Open Access article distributed under the terms of the Creative Commons Attribution License (http://creativecommons.org/licenses/by/2.0), which permits unrestricted use, distribution, and reproduction in any medium, provided the original work is properly cited.

\begin{abstract}
Background: The objectives of this retrospective study was to evaluate the efficacy of stereotactic body radiation therapy (SBRT) for small non-resectable hepatocellular carcinoma $(\mathrm{HCC})$ and SBRT combined with transarterial chemoembolization (TACE) for advanced $\mathrm{HCC}$ with portal vein tumor thrombosis (PVTT).

Methods: Thirty one patients with HCC who were treated with SBRT were used for the study. We studied $32 \mathrm{HCC}$ lesions, where 23 lesions (22 patients) were treated targeting small nonresectable primary HCC, and 9 lesions (9 patients) targeting PVTT using the Cyberknife. All the 9 patients targeting PVTT received TACE for the advanced HCC. Tumor volume was 3.6-57.3 cc (median, $25.2 \mathrm{cc}$ ) and SBRT dose was 30-39 Gy (median, $36 \mathrm{~Gy}$ ) in 3 fractions for consecutive days for $70-85 \%$ of the planned target volume.

Results: The median follow up was 10.5 months. The overall response rate was $71.9 \%$ [small HCC: 82.6\% (19/23), advanced HCC with PVTT: $44.4 \%(4 / 9)]$, with the complete and partial response rates of $31.3 \%$ [small HCC: $26.1 \%$ (6/23), advanced HCC with PVTT: I I.I\% (I/9)], and $50.0 \%$ [small HCC: $56.5 \%$ (13/23), advanced HCC with PVTT: $33.3 \%$ (3/9)], respectively. The median survival period of small HCC and advanced HCC with PVTT patients was 12 months and 8 months, respectively. No patient experienced Grade 4 toxicity.

Conclusion: SBRT for small HCC and SBRT combined with TACE for advanced HCC with PVTT showed feasible treatment modalities with minimal side effects in selected patients with primary $\mathrm{HCC}$.
\end{abstract}




\section{Background}

Primary hepatocellular carcinoma (HCC), which comprises $90 \%$ of all malignant cancers developed in the liver, is a fatal disease that might cause death with severe complications unless treated properly $[1,2]$. Many modalities such as surgical resection, percutaneous ethanol injection (PEI), radiofrequency ablation (RFA), Y90 microspheres, external radiation therapy (RT) and transarterial chemoembolization (TACE) have been tried in the treatment for HCC [3-8], but the optimal treatment approach remains controversial.

Stereotactic radiation therapy (SRT), for benign and malignant diseases, was initially used only for intracranial lesions. With the advent of advanced imaging techniques and robotic image-guided radiation technologies, the Cyberknife has extended highly conformal radiosurgery to extracranial SRT applications [9]. Stereotactic body radiation therapy (SBRT) is now being extended to more patients and clinical targets $[10,11]$. To date, there are only a few reports in the literature that assessed the response of HCC to SBRT [12-16]. We have employed SBRT, using the LINAC-based SBRT since 1995, with a special focus on liver tumors $[17,18]$. We performed LINAC-based SBRT for 20 primary HCC patients with the result of $80 \%$ local control, thus confirming that SBRT is helpful in the treating primary HCC.

Expanding our experience further, we have attempted SBRT alone for small primary non-resectable HCC, and used the combined therapy of TACE and SBRT for advanced HCC with portal vein tumor thrombosis (PVTT). Therefore, we evaluated the response rate and toxicity of SBRT for small primary non-resectable HCC and SBRT combined with TACE for advanced HCC with PVTT.

\section{Methods}

\section{Patients eligibility}

From March 2004 to March 2005, 31 patients participated in a retrospective study at the Cyberknife center, Catholic University. We treated 32 HCC lesions with the Cyberknife (Accuray Inc, Sunnyvale, CA) SBRT: 23 lesions (22 patients) of small non-resectable primary HCC were treated by SBRT while 9 lesions ( 9 patients) of PVTT in advanced HCCs were treated by SBRT combined with TACE. The criteria for patients to be included in the study were as follows: (1) patients with histologically proven primary HCC by ultrasound guided percutaneous needle biopsy of liver, (2) patients with active, enhancing HCC by radiography, (3) patients with PVTT surrounding near the HCC, not located at the distant, separate parenchyma, (4) patients not showing extrahepatic metastases, (5) patients with tumor size (maximal diameter) $\leq 5 \mathrm{~cm}$, (6) age $<75$, (7) patients with HCC that did not develop within the transplanted liver, (8) patients who had ECOG score $\leq 3$, (9) patients with no previous experience of radiotherapy and (10) patients with leukocytes $\geq 4,000 / \mu l$, platelet $\geq 50,000 / \mu l$. Written informed consent was obtained from all patients before therapy.

\section{Treatment and dose prescription}

In terms of previous treatment before SBRT, 17 of our patients had received TACE, 3 patients PEI, 6 patients RFA, and 5 patients had not received any previous treatment. All of these patients were those who needed another treatment modality such as conventional RT or SBRT because they, despite previous treatment, were either experiencing progression due to treatment failure or had refused further treatment due to poor tolerable state. TACE to gain a synergistic local effect and to visualize the location of the target. After the placement of a catheter, an emulsion of 10$20 \mathrm{mg}$ adriamycin in 3-10 ml lipiodol was infused into the artery that supplied the tumor. Then, embolization was performed with a variable amount of gelfoam depending upon the tumor size. TACE (range: $1-4$ times, median: 2 times) was performed after SBRT in patients with advanced HCCs with PVTT, whereas the patients in small HCC were treated with SBRT alone. The interval between TACE and SBRT was at least 4 weeks.

SBRT was administered using the Cyberknife image guided radiosurgery system. The treatment was planned to enclose the planning target volume (PTV) by the 70-85\% (median, 80\%) isodose line as the prescribed dose. Gross tumor volume (GTV) is defined as the tumor volume, which enhanced contrast at computer tomography (CT) scan. The PTV is defined as a $5 \mathrm{~mm}$ margin around the GTV. The total doses administered were 30-39 Gy (median, $36 \mathrm{~Gy}$ ) at PTV with the prescription isodose level range of $70-85 \%$ (median, $80 \%$ ) in 3 fractions over three consecutive days. The total treatment time per fraction was 2-2.5 hours and the inter-fraction interval was 24 hours at least.

\section{SBRT procedure and breath-holding technique}

Frameless SBRT was carried out at our institution using the Cyberknife SBRT system. Liver parenchyma around the tumor was implanted with four gold markers, which acted as radiographic landmarks for the image guidance system. In image-guided SBRT, the tumor position during treatment is always defined relative to the abdominal CT. The CT image was taken when breathing from the patient reached the maximum expiration. Treatment was delivered in the step, image and shoot sequence. First, the robot positioned the linear accelerator at a fixed beampointing position. Then, the patient took a breath and held it in exhalation while the imaging system acquired the targeting data. The patient then took a resting breath, followed by an RT breath-hold in exhalation, during which the treatment beam was turned on. Anywhere from 
Table I: Patient characteristics

\begin{tabular}{lccc}
\hline Characteristics & Small HCC & PVTT & Total \\
\hline $\begin{array}{l}\text { Number of patients } \\
\text { Number of lesions }\end{array}$ & 22 & 9 & 31 \\
Age (years) & 23 & 9 & 32 \\
$\quad$ Range & & & \\
$\quad$ Median & $44 \sim 78$ & $44 \sim 71$ & $44 \sim 78$ \\
Gender & 60 & 57 & 59 \\
$\quad$ Male & 14 & 5 & 19 \\
$\quad$ Female & 8 & 4 & 12 \\
Tumor volume (cc) & & & \\
$\quad$ Range & $3.6 \sim 57.3$ & $3.9 \sim 47.7$ & $3.6 \sim 57.3$ \\
$\quad$ Median & 23.5 & 32.8 & 25.2 \\
ECOG performance status & & & \\
$\quad$ 0-I & 18 & 6 & 24 \\
2 & 4 & 3 & 7 \\
Child-Pugh classification & & & \\
A & 19 & 7 & 26 \\
B & 3 & 2 & 5 \\
AJCC stage & & & \\
I & 8 & 0 & 8 \\
II & 14 & 0 & 14 \\
IIIA & 0 & 9 & 9 \\
\end{tabular}

ECOG, Eastern Cooperative Oncology Group, AJCC, American Joint Committee on Cancer

10 to 50 monitor units of RT were delivered at each beam position, broken up into breath-holding periods of 10-15 sec, depending on the pulmonary capacity of the patient. Once the complete dose for a particular beam direction had been delivered, the robot advanced the LINAC to the next beam position and the imaging/treatment cycle was repeated. The beam pointing during each RT breath-hold in exhalation was based on the tumor position observed during the most recent prior imaging during a breath-hold in exhalation. And the reproducibility of breath hold assessed was checked by skin marker and correlated, matched dot drawn on the monitor at the control room.

\section{Dose limitation to normal tissues}

The liver, stomach, duodenum, intestine, kidney, and spinal cords were contoured during the planning process and dose-volume histograms (DVH) were used to ensure that normal tissue tolerances were not exceeded.

\section{Liver}

Doses of 30-35 Gy in the whole liver with conventional fractionation are often considered to be the limit of liver tolerance. Kazunari Yamada et al. reported that the volume of the liver receiving a dose in excess of $30 \mathrm{~Gy}$, with conventional fractionation, could be used as a predictive test for damage in liver function [19]. We evaluated V20 as a predictor for liver damage accrued from the SBRT in our study: in the $\alpha / \beta$ ratio of $3,30-35$ Gy with conventional fractionation is equivalent to a dose of $3 \times 6 \mathrm{~Gy}$ (total, $18 \mathrm{~Gy}$ ) in the whole liver. The V20 was limited so as not to exceed $50 \%$ of the functional whole liver tissue.

\section{Stomach, duodenum and intestine}

Due to the lack of clinical data on the effect of very high fraction doses exceeding $8 \mathrm{~Gy}$, the dose of 7 Gy was chosen based on the experience in brachytherapy [20]. Therefore, the maximum dose to the stomach, duodenum, small or large bowel was limited to below 7 Gy per fraction (total, $21 \mathrm{~Gy}$ ) to avoid serious side effects.

\section{Kidney}

Emani et al. suggested $23 \mathrm{~Gy}$ for $\mathrm{TD}_{5 / 5}$ for whole-kidney irradiation [21]. Cassady reported that a threshold dose of 15 Gy delivered with conventional fractionation appeared reasonable [22]. As renal toxicities are usually related to the total volume of treated kidney, DVH are essential to predict renal toxicities. In this study, at least $2 / 3$ of the right kidney was limited to receive a dose of less than $5 \mathrm{~Gy}$ per fraction (total, $15 \mathrm{~Gy}$ ): in the $\alpha / \beta$ ratio of 3, $23 \mathrm{~Gy}$ with conventional fractionation is equivalent to a dose of $3 \times 5$ Gy (total 15 Gy).

\section{Spinal cord}

The maximum dose to the spinal cord was limited to below the $7 \mathrm{~Gy}$ per fraction from the linear-quadratic formula of Withers et al: for an $\alpha / \beta$ ratio of 3,42 Gy with conventional fractionation is equivalent to a dose of $3 \times 7$ Gy (total, 21 Gy) [23].

\section{Response and toxicity evaluation}

Patients underwent abdominal CT scans 1 month after completion of SBRT, and then tumor response was checked at 2-3 month intervals. Tumor responses were classified according to modification of the World Health Organization response evaluation criteria, as follows. Complete response (CR) was defined as complete disappearance of the irradiated tumor, partial response (PR) corresponded to more than $50 \%$ reduction in tumor volume, stable disease (SD) was defined as a decrease less than $50 \%$ or more than $25 \%$ in tumor volume, and progressive disease (PD) as more than $25 \%$ increase in tumor volume. CR and PR were defined as objective response.

For the 9 patients with advanced HCC with PVTT, final responses were analyzed after combined modality, SBRT and TACE were performed. Toxicity was evaluated according to the National Cancer Institute Common Toxicity Criteria for Events Version 2.0.

Analysis was performed after 31 patients had been enrolled. The survival time was measured as the period from the date of first SBRT to the date of death or the last follow-up. The survival rate was calculated according to the Kaplan-Meier method using SAS for window 8e. 
Table 2: Summary of primary HCC treated SBRT with or without transarterial chemoembolization

\begin{tabular}{|c|c|c|c|c|c|c|c|}
\hline No & Age & Sex & Tumor site & Tumor volume (cc) & SBRT dose (Gy) & Response & Status (months) \\
\hline 1 & 59 & $\mathrm{~F}$ & Right lobe & 25.0 & 30 & PR & $\mathrm{DOI}(2.0)$ \\
\hline 2 & 63 & $\mathrm{~F}$ & Right lobe & 5.4 & 36 & $C R$ & NED $(\mid 8.5)$ \\
\hline 3 & 52 & $\mathrm{~F}$ & Right lobe & 28.6 & 30 & PR & $A \& D(16.0)$ \\
\hline 4 & 57 & $\mathrm{~F}$ & Right lobe & 23.5 & 36 & CR & NED(I4.5) \\
\hline 5 & 78 & $M$ & Right lobe & 26.5 & 36 & CR & $\operatorname{NED}(\mid 4.0)$ \\
\hline 6 & 56 & $\mathrm{~F}$ & Right lobe & 31.9 & 36 & PR & $A \& D(\mid 3.0)$ \\
\hline 7 & 75 & $M$ & Right lobe & $25.2 / 27.5$ & $39 / 36$ & $\mathrm{SD} / \mathrm{CR}$ & $A \& D(\mid 3.0)$ \\
\hline 8 & 60 & $M$ & Right lobe & 36.5 & 36 & PR & $A \& D(12.5)$ \\
\hline 9 & 56 & M & Left lobe & 15.4 & 36 & $C R$ & $\operatorname{NED}(12.5)$ \\
\hline 10 & 70 & $\mathrm{~F}$ & Right lobe & 16.9 & 36 & SD & $A \& D(12.0)$ \\
\hline 11 & 44 & M & Right lobe & 16.6 & 30 & PR & $\operatorname{NED}(12.0)$ \\
\hline 12 & 48 & M & Right lobe & 35.1 & 30 & SD & $A \& D(12.0)$ \\
\hline 13 & 77 & $M$ & Right lobe & 33.3 & 33 & PR & DOI(II.5) \\
\hline 14 & 60 & $M$ & Right lobe & 6.9 & 36 & $C R$ & $A \& D(I I .0)$ \\
\hline 15 & 55 & $M$ & Right lobe & 12.0 & 36 & PR & $A \& D(10.0)$ \\
\hline 16 & 62 & $\mathrm{~F}$ & Right lobe & 31.3 & 30 & PR & $\mathrm{A} \& \mathrm{D}(9.0)$ \\
\hline 17 & 56 & $\mathrm{~F}$ & Right lobe & 17.6 & 33 & PR & $A \& D(9.0)$ \\
\hline 18 & 62 & $M$ & Right lobe & 21.6 & 30 & $S D$ & $A \& D(8.5)$ \\
\hline 19 & 75 & $M$ & Right lobe & 13.6 & 33 & PR & $A \& D(8.5)$ \\
\hline 20 & 48 & $M$ & Right lobe & 12.0 & 36 & PR & $A \& D(8.0)$ \\
\hline 21 & 62 & $M$ & Right lobe & 57.3 & 30 & PR & $A \& D(7.5)$ \\
\hline 22 & 67 & $M$ & Right lobe & 3.6 & 30 & PR & $A \& D(6.0)$ \\
\hline 23 & 57 & $M$ & Portal vein & 47.7 & 36 & $P R$ & $\operatorname{DOM}(2.0)$ \\
\hline 24 & 60 & $M$ & Portal vein & 16.2 & 36 & PR & $\operatorname{NED}(15.0)$ \\
\hline 25 & 46 & $\mathrm{~F}$ & Portal vein & 28.3 & 36 & SD & DOI(3.0) \\
\hline 26 & 71 & $\mathrm{~F}$ & Portal vein & 3.9 & 30 & SD & $A \& D(\mid 3.0)$ \\
\hline 27 & 44 & $M$ & Portal vein & 38.9 & 30 & SD & DOI(I2.0) \\
\hline 28 & 63 & $F$ & Portal vein & 34.7 & 30 & SD & $A \& D(8.5)$ \\
\hline 29 & 55 & $M$ & Portal vein & 37.0 & 30 & $C R$ & NED(8.0) \\
\hline 30 & 48 & $M$ & Portal vein & 23.7 & 30 & SD & DOI(7.0) \\
\hline 31 & 57 & $\mathrm{~F}$ & Portal vein & 32.8 & 30 & PR & $A \& D(6.0)$ \\
\hline
\end{tabular}

No, number, SBRT, stereotactic body radiation therapy, CR, complete response, PR, partial response, SD, stable disease, PD, progression disease, $\mathrm{DO}$, death of intercurrent disease, NED, no evidence of disease A\&D, alive of disease, DOM, death of metastatic disease.

\section{Results}

\section{Patients characteristics}

Pretreatment characteristics of patients and tumors are summarized in Table 1 . The median age was 59 years (range, 44-74 years), and males were predominant. The general condition of most patients was good, with 24 patients having ECOG scores of $0-1$. The median target volume was $25.2 \mathrm{cc}$ (range, 3.6-57.3 cc), $23.5 \mathrm{cc}$ (range, 3.6-57.3 cc) in small HCC and $32.8 \mathrm{cc}$ (range: 3.9-47.7 cc) in PVTT. The median follow-up for 31 patients was 10.5 months (range, 2.0-18.5 months), 11.5 months (range, 2.0-18.5 months) in small HCC and 8.5 months (range, 2.0-15.0 months) in PVTT. The summary of SBRT of patients is shown in Table 2 .

\section{Tumor response and survival to treatments}

The overall response rate (CR plus PR) was $71.9 \%(23 / 32)$ [small HCC: $82.6 \%(19 / 23)$, advanced HCC with PVTT: $44.4 \%$ (4/9)]. Of the 32 lesions, 7 (21.9\%) had a CR [small HCC - 26.1\% (6/23), advanced HCC with PVTT $11.1 \%(1 / 9)$ ] and $16(50.0 \%)$ a PR [small HCC - 56.5\% (13/23), advanced HCC with PVTT - 33.3\% (3/9)]. SD

Table 3: Response of primary HCC treated SBRT with or without transarterial chemoembolization

\begin{tabular}{lcc}
\hline Type of response & $\begin{array}{c}\text { Small HCC } \\
\text { No. of lesions(\%) }\end{array}$ & $\begin{array}{c}\text { PVTT } \\
\text { No. of lesions(\%) }\end{array}$ \\
\hline Complete response & $6(26.1)$ & $1(11.1)$ \\
Partial response & $13(56.5)$ & $3(33.3)$ \\
Stable disease & $4(17.4)$ & $5(55.6)$ \\
\hline
\end{tabular}



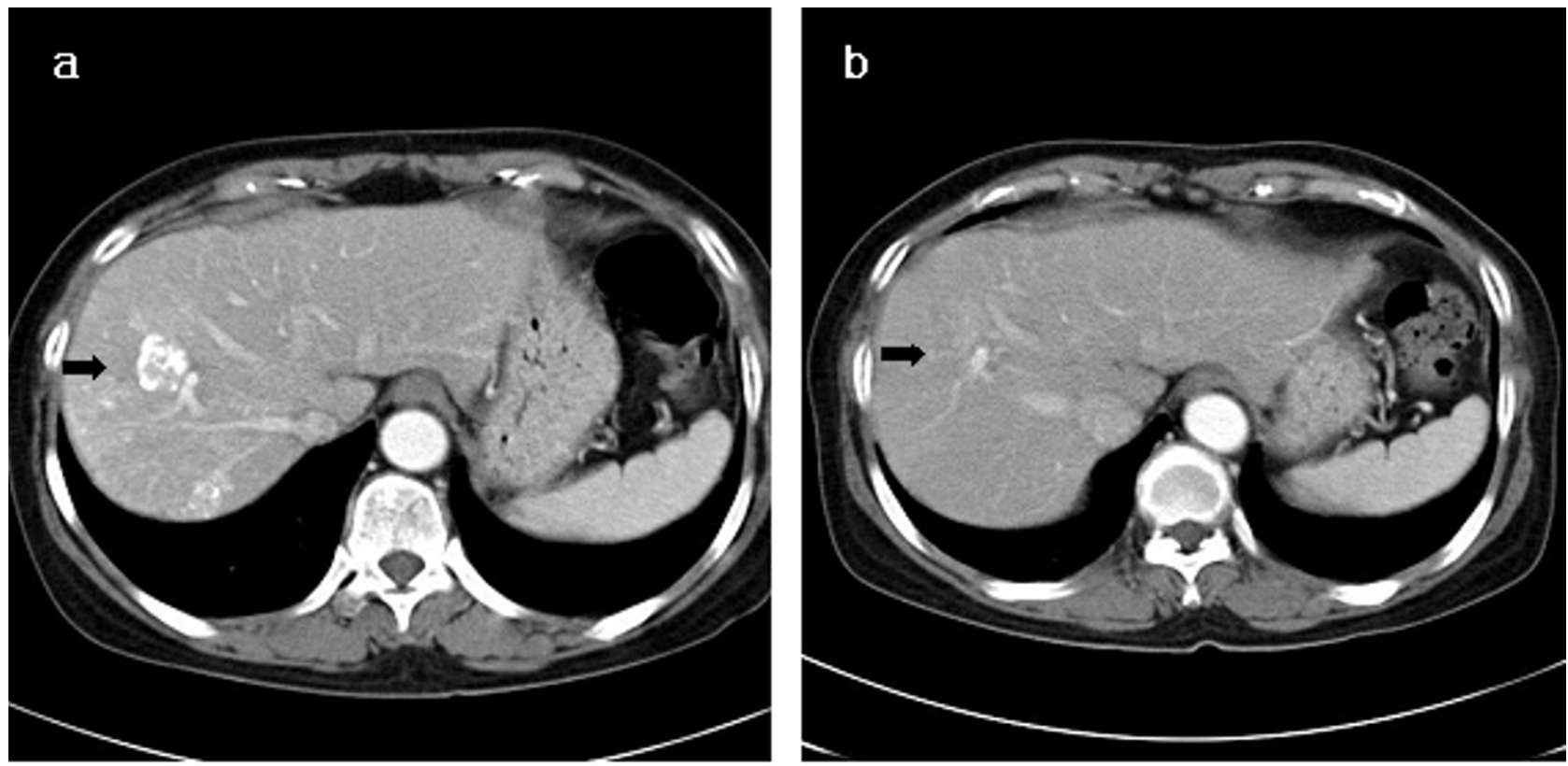

\section{Figure I}

(a) The initial abdominal CT scan with the primary HCC indicated by the arrow. (b) CT scan seven months after SBRT. This patient was classified as PR at 5 months after SBRT. (SBRT, stereotactic body radiation therapy).

disease was documented in $9(28.1 \%)$ lesions [small HCC: $17.4 \%$ (4/23), advanced HCC with PVTT: $55.6 \%$ (5/9)] (Table 3). Figure 1, 2 shows the result for patients who were classified as PRs. The median survival of all

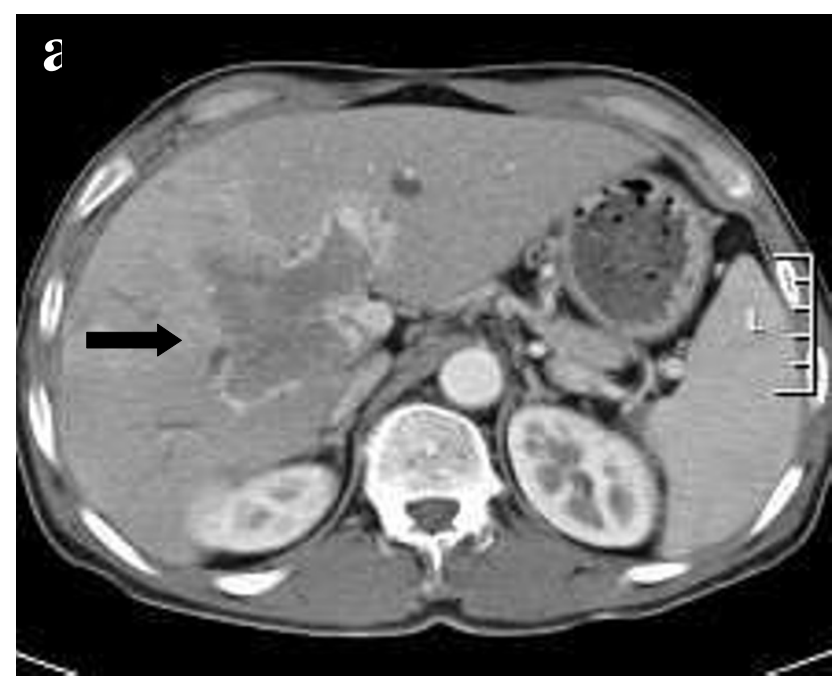

patients was 11.5 months, with 1 -year survival rate of $81.4 \%$. Among patients of small HCC, the median survival time was 12 months and the 1 -year survival rate was $88.1 \%$. The median survival time and 1 -year survival rate

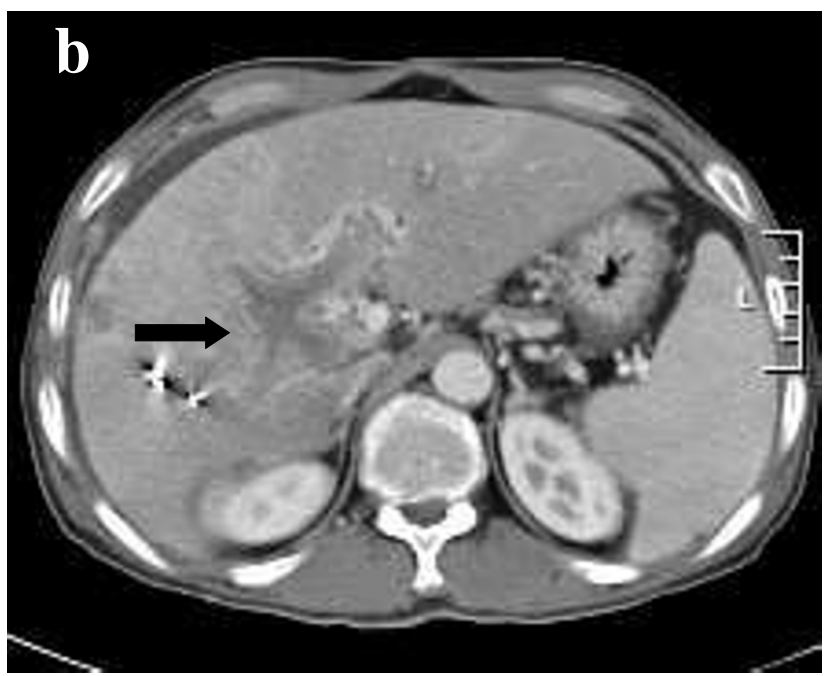

\section{Figure 2}

(a) The initial abdominal CT scan with the PVTT indicated by the arrow. (b) CT scan two months after SBRT and three courses course of TACE. This patients was classified as PR at 2 months after SBRT. (SBRT, stereotactic body radiation therapy). 


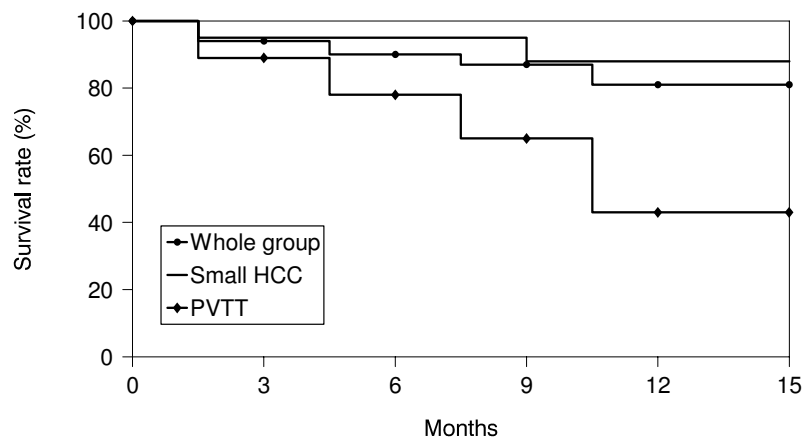

Figure 3

Actuarial overall survival curve.

for advanced HCC with PVTT was 8 months and $43.2 \%$ (Figure 3). Local recurrence was observed in 3 lesions, observed in small HCC (1) and advanced HCC with PVTT (2). At the time of analysis, 6 patients had died of disease and 25 patients were alive.

\section{Toxicity}

The frequency of treatment related toxicities including liver enzymes, bilirubin, albumin, leukocytes, platelets, and nausea toxicities is presented in Table 4 . Of the 31 patients, one patient experienced grade 3 liver enzymes toxicity in small HCC. There were no treatment related deaths.

Five patients (16.1\%) showed progression of Child-Pugh classification from A to B within 3 months after SBRT (3 small HCC, 2 advanced HCC with PVTT). Three of them had progressive disease in 1-2 months after SBRT. Progression from Child-Pugh classification B after SBRT was not observed.

\section{Discussion}

Surgical resection has been considered a preferred modality of treatment for long-term control of some limited HCCs. However, less than $20 \%$ of patients are surgical candidates at diagnosis. In recent years, a number of alternative local modalities including PEI, TACE and RFA have been developed. These local treatments have shown local control rates of $86 \%$ after PEI [4], local control rates for liver metastasis of 70\% after RFA [5] and 55\% after TACE [6]. Seong JS et al. studied the combination of conformal RT with TACE for HCC and local control rates of $66 \%$ have been reported in patients [24]. As a result of our study, the local control rate was observed to be $71.9 \%$, which is at least equivalent to the invasive local therapies. Therefore, considering the quality of life during and following treatment and the noninvasive, painless approach

\begin{tabular}{|c|c|c|}
\hline Toxicity & Small HCC & PVTT \\
\hline \multicolumn{3}{|c|}{ Liver enzymes, grade } \\
\hline 0 & 14 & 4 \\
\hline I & 7 & 5 \\
\hline 2 & 0 & 0 \\
\hline 3 & 1 & 0 \\
\hline 4 & 0 & 0 \\
\hline \multicolumn{3}{|c|}{ Bilirubin, grade } \\
\hline 0 & 18 & 7 \\
\hline I & 4 & 2 \\
\hline 2 & 0 & 0 \\
\hline 3 & 0 & 0 \\
\hline 4 & 0 & 0 \\
\hline \multicolumn{3}{|c|}{ Albumin, grade } \\
\hline 0 & 19 & 7 \\
\hline I & 3 & 2 \\
\hline 2 & 0 & 0 \\
\hline 3 & 0 & 0 \\
\hline 4 & 0 & 0 \\
\hline \multicolumn{3}{|c|}{ Leukocytes, grade } \\
\hline 0 & 17 & 6 \\
\hline I & 5 & 1 \\
\hline 2 & 0 & 2 \\
\hline 3 & 0 & 0 \\
\hline 4 & 0 & 0 \\
\hline \multicolumn{3}{|c|}{ Platelets, grade } \\
\hline 0 & 19 & 5 \\
\hline I & 3 & 3 \\
\hline 2 & 0 & 1 \\
\hline 3 & 0 & 0 \\
\hline 4 & 0 & 0 \\
\hline \multicolumn{3}{|c|}{ Nausea, grade } \\
\hline 0 & 11 & 3 \\
\hline I & 10 & 6 \\
\hline 2 & 1 & 0 \\
\hline 3 & 0 & 0 \\
\hline 4 & 0 & 0 \\
\hline
\end{tabular}

associated with SBRT, this technique may be a preferred treatment modality for primary HCC.

Clinically, the biologic advantage of a larger volume of potential normal tissue repair, such as that occurs with conventional RT, is of particular importance when the safety margin is small between tumor and normal tissue. If the irradiated volume is restricted to the tumor with a very small security margin, sublethal damage repair is not a first-line aim because complete cell damage is intended. SBRT can create a high-gradient dose falloff in the target tumor with a very small security margin.

Dose escalation appears to be a very important issue for local control rates. If HCC is treated with RT alone, it requires normal liver tissue-sparing radiation techniques, because the tolerance dose of the liver declines with the volume irradiated [25]. However, dose escalation with 
conventional RT is limited by prolonged treatment time (accelerated tumor cell repopulation) and increase of the dose to the functional liver tissue (impairment of liver function). SBRT can deliver a high dose of radiation to the target tissue with a high degree of precision within the body [26], while sparing most of the adjacent organ, resulting in potentially better local control and lower risk for RT toxicity.

Published clinical data on SBRT, especially for liver tumors, is limited [12-16]. Blomgren et al. published the first experiences of use of stereotactic RT for liver tumors [27]. They recommend a hypofractionated RT approach with an inhomogeneous dose distribution in the target. Herfarth KK et al. used a stereotactic single dose RT approach in the treatment of liver tumors [12]. In these studies, both demonstrated high local tumor control rate and low morbidity. The present study on SBRT was attempted based on the results from the above researches, and the results of this study confirmed that SBRT is indeed helpful in the patients of small HCC.

The presence of PVTT is an extremely poor prognostic factor, because it can lead not only to, the wide dissemination of tumors throughout the liver due to the presence of arterioportal shunting, but also to marked worsening of the liver function as a result of decreased portal flow. In patients with PVTT, TACE was considered a contraindication because it could theoretically result in hepatic damage resulting from hepatic ischemia [28]. TACE is less effective in patient with PVTT, and local RT may make TACE more effective if portal vein disease can be eradicated [29]. Tazawa et al. reported a retrospective study of combined therapy (local RT + TACE) in 24 patients with PVTT [30]. In their study, the survival rate was significantly better in the responders than the non-responders. However, Yamada et al. reported 19 patients who had combined therapy (local RT + TACE) with PVTT; They found no significant difference in overall survival between the responders and non-responders [19]. However, one significant finding in this study was that on follow-up angiograms, the protrusion of PVTT into the main portal trunk decreased in all cases. Combined therapy (local RT + TACE) may prevent PVTT from spreading to the main trunk, suggesting a further benefit of TACE. Because the time frame for the RT period in this study was at least 6 weeks, in many cases, the tumor outside the RT fields continued to be enlarged after RT. A shorter fractionation schedule of SBRT like our study will be able to resolve this problem. Our policy, in combining RT with TACE, was to use SBRT solely to treat PVTT in a short treatment period, whereas intralobar HCC was treated with TACE. SBRT, for primary HCC with PVTT, has shown acceptable local control.
In our study, we observed three patients with local recurrence in tumor of left hepatic lobe of the liver. All of the local recurrence are regarded to resulting from marginal recurrence due to inaccurate treatment of a moving target and the poor breathing capacity of the patients. The magnitude of respiration-induced target motion could be as large as $2-3 \mathrm{~cm}$, peak-to-peak. Various methods have been proposed to control or mitigate target motion. These include active or passive breath-holding techniques [31], respiratory gating [32] and 4 dimension or tumor tracking [33]. Breath-holding techniques, by either actively or passively suspending the patient's respiration, allow treatment during this interval. A study examining intra- and interfraction reproducibility of diaphragm position within a fraction can be reproduced satisfactorily. However, daily imaging and repositioning are still required in order to achieve any appreciable reduction in treatment margin for precise treatment. Meanwhile, we suggest to select future patients with well tolerable breathing or train patient to maintain stable breathing, in order to avoid inaccurate treatment of a moving target.

\section{Conclusion}

Our study shows that SBRT for small HCC and a combination of SBRT with TACE for advanced HCC with PVTT are feasible and effective treatments. Further study is necessary to define the role of dose administered as well as fractionation and side effects in selected patients with small primary HCC and advanced HCC with PVTT.

\section{Competing interests}

The authors declare that they have no competing interests.

\section{Authors' contributions}

BOC, IBC, HSJ, YNK, JSJ, SHB, SKY, GYC and KMK have made substantial contributions to conception and design of the study. BOC, IBC, HSJ, SHB, SKY and KMK carried out acquisitions of data. BOC, IBC, HSJ, YNK, JSJ, GYC and $\mathrm{KMK}$ carried out analysis and interpretation of data. BOC, IBC, HSJ, GYC and KMK have been involved in drafting the manuscript.

\section{Acknowledgements}

This study was presented at the 43th Annual Meeting of the American Society of Clinical Oncology, Chicago, Illinois, June I-5, 2007.

\section{References}

I. Okuda K, Ohtsuki T, Obata H, Tomimatsu M, Okazaki N, Hasegawa $\mathrm{H}$, Nakajima Y, Ohnishi K: Natural history of hepatocellular carcinoma and prognosis in relation to treatment. Study of $\mathbf{8 5 0}$ patients. Cancer 1985, 56:918-928.

2. Blum HE: Hepatocellular carcinoma: therapy and prevention. World J Gastroenterol 2005, I I:7391-7400.

3. Befeler AS, Di Bisceglie AM: Hepatocellular carcinoma: diagnosis and treatment. Gastroenterology 2002, 122:1609-1619.

4. Orlando A, Cottone M, Virdone R, Parisi P, Sciarrino E, Maringhini A, Caltagirone M, Simonetti RG, Pagliaro L: Treatment of small hepatocellular carcinoma associated with cirrhosis by percu- 
taneous ethanol injection: a trial with a comparison group. Scan J Gastroenterol 1997, 32:598-603.

5. Solbiati L, lerace T, Tonolini M, Osti V, Cova L: Radiofrequency thermal ablation of hepatic metastasis. Eur J Ultrasound $200 \mathrm{I}$ 13:149-158.

6. Kulik LM, Carr BI, Mulcahy MF, Lewandowski RJ, Atassi B, Ryu RK Sato KT, Benson A 3rd, Nemcek AA Jr, Gates VL, Abecassis M, Omary RA, Salem R: Safety and efficacy of $90 Y$ radiotherapy for hepatocellular carcinoma with and without portal vein thrombosis. Hepatology 2008, 47:7I-8I.

7. Ben-Josef E, Lawrence TS: Radiotherapy for unresectable hepatic malignancies. Semin Radiat Oncol 2005, I5:273-278.

8. Bruix J, Llovet JM, Castells A, Montana X, Bru C, Ayuso MC, Vilana R, Rodes J: Transarterial embolization versus symptomatic treatment in patients with advanced hepatocellular carcinoma: results of a randomized, controlled trial in a single institution. Hepatology 1998, 27:1578-1583.

9. Sarfaraz M: CyberKnife robotic arm stereotactic radiosurgery. J Am Coll Radiol 2007, 4:563-565.

10. Koong AC, Christofferson E, Le OT, Goodman KA, Ho A, Kuo T, Ford JM, Fisher GA, Greco R, Norton J, Yang GP: Phase II study to assess the efficacy of conventionally fractionated radiotherapy followed by a stereotactic radiosurgery boost in patients with locally advanced pancreatic cancer. Int J Radiat Oncol Biol Phys 2005, 63:320-323.

II. Nuyttens J], Prévost JB, Praag J, Hoogeman M, Van Klaveren RJ, Levendag PC, Pattynama PM: Lung tumor tracking during stereotactic radiotherapy treatment with the CyberKnife: Marker placement and early results. Acta Oncol 2006, 45:96I-965.

12. Herfarth KK, Debus J, Lorth F, Bahner ML, Rhein B, Fritz P, Höss A, Schlegel W, Wannenmacher MF: Stereotactic single-dose radiation therapy of liver tumors: results of a phase I/II trial. J Clin Oncol 200I, 19:164-170.

13. Schefter TE, Cardenes HR, Kavanagh BD: Stereotactic body radiation therapy for liver tumors. In: Kavanagh BD, Timmerman RD eds. Stereotactic body radiation therapy. Philadelphia: Lippincott Williams \& Wilkins; 2005: I I5- 27.

14. Dawson LA, Jaffray DA: Advances in image-guided radiation therapy. J Clin Oncol 2007, 25:938-46.

15. Takeda A, Takahashi M, Kunieda E, Takeda T, Sanuki N, Koike Y, Atsukawa K, Ohashi T, Saito H, Shigematsu N, Kubo A: Hypofractionated stereotactic radiotherapy with and without transarterial chemoembolization for small hepatocellular carcinoma not eligible for other ablation therapies: Preliminary results for efficacy and toxicity. Hepatol Res 2008, 38:60-69.

16. Tse RV, Hawkins M, Lockwood G, Kim JJ, Cummings B, Knox J, Sherman $M$, Dawson LA: Phase I study of individualized stereotactic body radiotherapy for hepatocellular carcinoma and intrahepatic cholangiocarcinoma. J Clin Oncol 2008, 26:657-664

17. Kang KM, Choi IB, Kim IA, Choi BO: Preliminary result in patients with primary hepatoma treated with stereotactic radiotherapy. J Korean Soc Ther Radiol Oncol 200I, 19:34-39.

18. Choi BO, Jang HS, Kang KM, Lee SW, Kang YN, Chai GY, Choi IB. Fractionated stereotactic radiotherapy in patients with primary hepatocellular carcinoma. Jpn J Clin Oncol 2006 36:154-158.

19. Yamada K, Izaki K, Sugimoto K, Mayahara H, Morita Y, Yoden E, Matsumoto $S$, Soejima T, Sugimura K: Prospective trial of combined transcatheter arterial chemoembolization and three-dimensional conformal radiotherapy for portal vein tumor thrombus in patients with unresectable hepatocellular carcinoma. Int J Radiat Oncol Biol Phys 2003, 57: I I3-I I9.

20. Orton CG, Seyedsadar M, Somnay A: Comparison of high and low dose rate remote afterloading for cervix and the importance of fractionation. Int J Radiat Oncol Biol Phys 1991, 21:1425-1434.

21. Emami B, Lyman J, Brown A, Coia L, Goitein M, Munzenrider JE, Shank $B$, Solin LJ, Wesson M: Tolerance of normal tissue to therapeutic irradiation. Int J Rad Oncol Biol Phys 1991, 21:109-122.

22. Cassady JR: Clinical radiation nephropathy. Int J Rad Oncol Biol Phys 1995, 31: 1249-1256.

23. Withers HR, Thames HD Jr, Peters LJ: A new isoeffect curve for change in dose per fraction. Radiother Oncol 1983, I:187-191.

24. Seong J, Park HC, Han KH, Chon CY, Chu SS, Kim GE, Suh CO: Clinical results of 3-dimensional conformal radiotherapy combined with transarterial chemoembolization for hepatocellular carcinoma in the cirrhotic patients. Hepatology Research 2003, 27:30-35

25. Park HC, Seong J, Han KH, Chon CY, Moon YM, Suh CO: Doseresponse relationship in local radiotherapy for hepatocellular carcinoma. Int J Radiat Oncol Biol Phys 2002, 54:I50-155.

26. Chang SD, Main W, Martin DP, Gibbs IC, Heilbrun MP: An analysis of the accuracy of the CyberKnife: A robotic frameless stereotactic radiosurgical system. Neurosurgery 2003, 52: I 40-147.

27. Blomgren $\mathrm{H}$, Lax I, Goranson $\mathrm{H}$ : Radiosurgery for tumors in the body: Clinical experience using a new method. J Radiosurgery 1998, I:63-74.

28. Yamada R, Sato M, Kawabata M, Nakatsuka $H$, Nakamura $K$ Takashima S: Hepatic artery embolization in 120 patients with unresectable hepatoma. Radiology 1983, I48:397-40I.

29. Hawkins MA, Dawson LA: Radiation therapy for hepatocellular carcinoma: from palliation to cure. Cancer 2006, 106:1653-1663.

30. Tazawa J, Maeda M, Sakai Y, Yamane M, Ohbayashi H, Kakinuma S, Miyasaka $Y$, Nagayama K, Enomoto N, Sato C: Radiation therapy in combination with transcatheter arterial chemoembolization for hepatocellular carcinoma with extensive portal vein involvement. J Gastroenterol Hepatol 200I, 16:660-665.

31. Rosenzweig KE, Hanley J, Mah D, Mageras G, Hunt M, Toner S, Burman C, Ling CC, Mychalczak B, Fuks Z, Leibel SA: The deep inspiration breath-hold technique in the treatment of inoperable non small-cell lung cancer. Int J Radiat Oncol Biol Phys 2000, 48:8I-87.

32. Ford EC, Mageras GS, Yoke E, Rosenzweig KE, Wagman R, Ling CC: Evaluation of respiratory movement during gated radiotherapy film and electronic portal imaging. Int J Radiat Oncol Biol Phys 2002, 52:522-531.

33. Shirato H, Shimizu S, Kunieda T, Kitamura K, van Herk M, Kagei K, Nishioka T, Hashimoto S, Fujita K, Aoyama H, Tsuchiya K, Kudo K, Miyasaka K: Physical aspects of a real-time tumor tracking system for gated radiotherapy. Int J Radiat Oncol Biol Phys 2000, 48: $1187-1195$.

\section{Pre-publication history}

The pre-publication history for this paper can be accessed here:

http://www.biomedcentral.com/1471-2407/8/351/pre pub

Publish with Bio Med Central and every scientist can read your work free of charge

"BioMed Central will be the most significant development for disseminating the results of biomedical research in our lifetime. "

Sir Paul Nurse, Cancer Research UK

Your research papers will be:

- available free of charge to the entire biomedical community

- peer reviewed and published immediately upon acceptance

- cited in PubMed and archived on PubMed Central

- yours - you keep the copyright
BioMedcentral 